\title{
Entre a Frieza, o Cálculo e a "Vida Loka": violência e sofrimento no trajeto de um adolescente em cumprimento de medida socioeducativa
}

\section{Between Coldness, Calculation and "Crazy Life": violence and suffering in an adolescent's trajectory while complying with a social-educational measure}

\author{
Paulo Artur Malvasi \\ Doutorando em Saúde Pública pela FSP/USP. Docente e Pesquisador \\ do Programa de Mestrado Profissional Adolescentes em Conflito \\ com a Lei da Universidade Bandeirante de São Paulo. \\ Endereço: Rua Dr. Homem de Melo, 514, apt 12, CEP 05007-00I, \\ São Paulo, SP, Brasil. \\ E-mail: paulomalvasiळhotmail.com
}

\section{Resumo}

O conceito de sofrimento social caracteriza-se pela compreensão das situações de aflição e dor como experiências sociais e não como problemas individuais. Este trabalho analisa a natureza social e política do sofrimento de um adolescente em cumprimento de medida socioeducativa. Inspirado na abordagem de Veena Das, o artigo se apóia em "carne" e discurso para problematizar a relação entre cidadania e segmentos juvenis discriminados, que se manifesta nas ambiguidades das práticas institucionais presentes no fluxo de execução de medidas socioeducativas. 0 artigo analisa as contradições entre o objetivo institucional de evitar a reincidência de atos infracionais, auxiliando o adolescente a tornar-se um cidadão autônomo, e as narrativas e expressões corporais dos adolescentes durante o cumprimento das medidas. A trajetória aqui descrita leva ao reconhecimento de que o trânsito da medida de internação para as medidas em meio aberto se dá sob a tensão entre o discurso institucional de reorganizar a vida escolar, familiar e comunitária e a experiência cotidiana dos adolescentes, que segue marcada pela constante ameaça policial e pela privação de acessos a bens públicos. O cumprimento de medidas socioeducativas acaba por reforçar entre os adolescentes a aflição de serem socialmente tidos como suspeitos e fugitivos e, consequentemente, a incorporação de um lugar social particular, o de membro do "mundo do crime". O desempenho na vida cotidiana de um "estilo bandido" revela for- 
mas de resposta ao discurso dominante no sistema socioeducativo, contexto que indica o paradoxo do Estado brasileiro, que garante uma democracia formal enquanto viola direitos civis.

Palavras-chave: Adolescente; Medida Socioeducativa; Sofrimento Social; Violência; Etnografia.

\section{Abstract}

The concept of social suffering is marked by the understanding of affliction and pain situations as social experiences, rather than psychological or medical individual problems. This paper analyses the social and political nature of an adolescent's suffering while he is complying with a social-educational measure. Based on Veena Das' approach, the paper relies on "body" and speech in order to raise the issue of the relation between citizenship and discriminated youth segments that is manifested in the ambiguities of the institutional practices that are present in the execution flow of social-educational measures. The article analyses the contradictions between the institutional aim of avoiding the recidivism of infraction acts, helping the adolescent become an autonomous citizen, and the adolescents' narratives and body expressions while complying with the measure. The ethnographical experience described here leads to the examination of ambiguities present in the transit from freedom privation to open environment measures. This transit occurs under tensions between the institutional discourse of re-organizing the community, family and school life and the adolescents' daily experience, which continues to be marked by constant police threat and privation of access to public property. Complying with social-educational measures seems to reinforce among adolescents the affliction of being socially seen as suspects and runaways, as well as the incorporation of a particular social place: member of "the world of crime". The performance in daily life of a "criminal lifestyle" reveals ways of answering to the dominant discourse in the socio-educational system; a context that indicates the paradox of the Brazilian State, which guarantees a formal democracy while violates civil rights.

Keywords: Adolescent; Social-Educational Measure; Social Suffering; Violence; Ethnography. 


\section{Introdução}

O conceito de sofrimento social caracteriza-se pela compreensão das situações de aflição e dor como experiências sociais e não como problemas individuais. Essa abordagem permite a investigação das experiências individuais de sofrimento em diferentes contextos, observando as ambiguidades das práticas institucionais voltadas para abrandar o sofrimento dos sujeitos tidos como excluídos e vulneráveis e que, paradoxalmente, resultam em sua intensificação (Kleinman e col., 1997). Este artigo propõe discutir o sofrimento presente na experiência de um adolescente durante o cumprimento de medidas socioeducativas ${ }^{1}$. A pesquisa que embasa este trabalho ${ }^{2}$ se realizou junto a adolescentes de ambos os sexos em cumprimento de medidas em meio aberto (liberdade assistida e prestação de serviços à comunidade) em duas localidades do Estado de São Paulo. Durante o ano de 2009, acompanhei a trajetória de 12 adolescentes.

Na pesquisa de campo, mergulhei no cotidiano de jovens que passaram por essas medidas, frequentei o território em que residem, conhecendo suas famílias e amigos, acompanhei os fluxos de significados, práticas e performances de sua vida cotidiana. A criação de vínculos com os adolescentes se deu por diferentes entradas no campo. Em uma das localidades (um bairro da cidade de Campinas), o contato com os adolescentes foi mediado por uma organização responsável pela execução de medidas em meio aberto. No outro local (uma cidade média do interior do Estado), conheci o território, as famílias, as lideranças comunitárias, fato que permitiu acompanhar o cotidiano dos adolescentes a partir da experiência comunitária.

Minha inserção no campo foi complexa, pois, além de realizar pesquisas no terreno dos próprios adolescentes, sou professor do Programa de Mestra- do Adolescentes em Conflito com a Lei, cujos alunos são profissionais de diversas áreas relacionadas ao trabalho com esse grupo: psicólogos, defensores públicos, promotores, policiais, assistentes sociais, educadores etc. Meus alunos - que muitas vezes experimentam as mesmas contradições que eu - ocupam posições institucionais em órgãos do Estado e em organizações de defesa de direitos e de execução de políticas sociais. Sou, ainda, diretor de uma Organização Não Governamental que atende crianças e adolescentes em um território considerado foco de "vulnerabilidades" e de "violências". Esta pesquisa, portanto, realizou-se em um terreno de fronteiras: a violência institucional, que combato, é reproduzida por um campo institucional em que, de certa forma, atuo. Lembro, por isso, aos meus alunos, que a antropologia não serve para "pacificar", mas para "manter o mundo em desequilíbrio, puxando tapetes, virando mesas e soltando rojões". O ofício do antropólogo é como o de um "mercador do espanto" (Geertz, 2001).

Se a antropologia tem algum papel importante no mundo, este é o da provocação - o desafio de atualizar constantemente a compreensão das experiências humanas, sobretudo daquelas estigmatizadas. Neste artigo, procurarei interpretar a natureza social e política do sofrimento de um adolescente em cumprimento de medidas socioeducativas: a privação de liberdade, em um primeiro momento, e, em seguida, o cumprimento da medida de liberdade assistida. Parto aqui do pressuposto de que o antropólogo é um cientista social para quem a interação é o principal meio de pesquisa. A interação do antropólogo com os "nativos", entretanto, não se caracteriza por uma improvável capacidade em traduzir o "verdadeiro espírito" do "outro". A pesquisa antropológica é, antes de tudo, a busca de capturar os atos e as falas em ação e a elaboração de teorias etnográficas - expressão "que serve para solucionar

\footnotetext{
1 No Estatuto da Criança e do Adolescente (Brasil, 199o), o ato infracional praticado por adolescentes deve receber a aplicação de medidas de proteção, pois os menores de 18 anos são "penalmente inimputáveis" (Brasil, 1990, artigo 104). As medidas socioeducativas dividem-se entre as que são executadas em meio aberto (advertência, reparação do dano, prestação de serviços à comunidade, liberdade assistida) e as de privação de liberdade (semiliberdade e internação em estabelecimento educacional). As medidas são operadas por um sistema que envolve o poder judiciário, que as aplica, organizações estatais especializadas na medida de privação de liberdade e poderes públicos e instituições civis responsáveis pela execução das medidas em meio aberto.

2 "Práticas cotidianas e representações sobre a vida coletiva entre adolescentes em conflito com a lei", pesquisa realizada junto à linha de pesquisa "Adolescente em Conflito com a Lei: violência, sociedade e criminalidade", Mestrado Profissional Adolescente em Conflito com a Lei/Universidade Bandeirante de São Paulo, de setembro de 2008 a outubro de 2010
} 
o dilema do antropólogo, preso entre a ciência e a narrativa, o discurso sobre os outros e o diálogo com eles" (Goldman, 2006, p. 170). 0 trabalho etnográfico que proponho procura localizar um adolescente no sistema socioeducativo através de sua experiência, suas relações e suas interações com os "outros": os técnicos do sistema, a mãe, os amigos, o próprio pesquisador. 0 trabalho é aproximar-se do ordinário, recuperar as vozes das pessoas e descrever o modo como os sentimentos com relação à violência são incorporados em sua vida cotidiana (Das, 2007). A escolha da trajetória de um entre os 12 adolescentes que participaram da pesquisa se configurou em uma estratégia descritiva, que está em consonância com a abordagem de Veena Das. Essa abordagem traz uma experiência concreta e visível para discutir o sofrimento social ${ }^{3}$.

A partir de minhas observações, analisei as contradições entre o objetivo institucional de evitar a reincidência de atos infracionais, auxiliando o adolescente a tornar-se um cidadão autônomo, e as narrativas e expressões corporais desse adolescente durante o cumprimento das medidas. A pesquisa de campo levou-me à problematização da relação entre cidadania e segmentos juvenis discriminados, que se manifesta nas ambiguidades do trânsito da privação de liberdade para as medidas em meio aberto. Essa passagem se dá sob a tensão entre o discurso institucional, que pretende reorganizar a vida escolar, familiar e comunitária dos adolescentes, e a experiência cotidiana deles, que segue marcada pela constante ameaça policial e, ainda, pela privação do acesso a lugares públicos, de um lado, e pelo desejo de afirmação junto aos pares, de outro.

$\mathrm{O}$ artigo discute inicialmente o contexto de surgimento das medidas socioeducativas, sua relação intrínseca com segmentos juvenis discriminados e as contradições entre punição e educação que elas ensejam. Na sequência, segue a descrição etnográfica para a interpretação do sofrimento social entre adolescentes que cumprem medidas em meio aberto após terem passado pela medida de privação de liberdade.

\section{Medidas Socioeducativas: desvelando o contexto}

Baseado na doutrina de proteção integral, o Estatuto da Criança e do Adolescente (ECA), Lei no 8069/9o, representa um esforço de superação da política instituída para o "menor" pela Funabem (Fundação Nacional de Amparo e Bem-Estar do Menor). Na área do adolescente autor de ato infracional, o ECA representou um avanço ao instituir o direito ao devido processo legal, o direito à defesa e a ênfase na ideia de que as medidas deveriam privilegiar o caráter socioeducativo ${ }^{4}$. Esse esforço, empreendido por movimentos sociais, intelectuais e militantes dos direitos humanos apresentou, "no plano jurídico e político", uma mudança de referências, "não chegando efetivamente aos seus destinatários" (Brasil, 2005, p. 8).

Desde a segunda metade da década de 1970, estudos revelaram a situação de adolescentes considerados "marginais" e as estratégias do Estado para ajustar sua conduta. O comportamento dos "menores marginalizados" foi pensado como parte da doutrina intrínseca de um posicionamento diante do sistema sociopolítico e econômico de que participam (Schneider, 1982), uma forma de adaptação aos valores sociais dominantes e de desenvolvimento de "estratégias de sobrevivência" (Ferreira, 1980). A abordagem da ação do Estado nesses trabalhos implicaria uma atitude de denúncia, visando diminuir o poder institucional de punir arbitrariamente (idem), ou em um posicionamento crítico diante de uma sociedade desigual e excludente (Schneider, 1982). A Febem (Fundação Estadual de Bem-Estar do Menor) foi identificada como uma instituição

3 João Coin Carvalho (2008) discute os trabalhos da antropóloga indiana Veena Das como uma referência para o estudo de situações de violência e sofrimento social. Carvalho destaca a construção de "quase personagens" como abordagem metodológica e descritiva para a sustentação das teses da autora: "materializar na história e no corpo o sofrimento faz seu argumento ganhar força na medida em que se afasta de uma abstração e se apóia em carne e discurso” (Carvalho, 2008, p. 13).

4 A compreensão de medidas socioeducativas no ECA parte da noção de proteção integral da criança e do adolescente, delimitando os direitos das crianças e dos adolescentes assim como as responsabilidades do estado e da sociedade. Segundo o artigo 113 "na aplicação das medidas levar-se-ão em conta as necessidades pedagógicas, preferindo aquelas que visem ao fortalecimento dos vínculos familiares e comunitários" (Brasil, 2005). 
com visão estigmatizada dos adolescentes. Os temas da "reintegração" (ou "reeducação" ou "ressocialização") foram discutidos em sua ambiguidade: ao impor ao adolescente uma identidade idealizada, a intervenção da Febem produzia efeitos contrários àqueles que se propunha, aproximando o jovem de seus pares ("grupo de iguais") e o distanciando dos valores da "integridade social" do mundo adulto (Violante, 1982).

A produção intelectual e militante dos anos 1980 - que os trabalhos citados, dentre outros, representam - constituiu a mobilização que levou à elaboração do ECA. A promulgação do estatuto em 1990 representou uma conquista dessa geração e a possibilidade de abertura para novos modelos de ação junto ao adolescente autor de ato infracional, ancoradas em um esforço pedagógico em torno de práticas socioeducativas. Destaca-se nesse campo a produção de Antônio Carlos Gomes da Costa (2001), que a partir da sistematização de uma reconhecida experiência como diretor de uma unidade da Febem ${ }^{5}$, tornou-se o principal difusor de práticas socioeducativas. Costa (2001) apresenta a proposta de uma "pedagogia da presença" para o reconhecimento da "imensa vontade de ser aceito, de viver e libertar-se" do adolescente. A obra do pedagogo coloca em perspectiva o tema da socialização. 0 comportamento ajustado, a adaptação total às leis e normas que presidem o funcionamento da sociedade, em suma, a renúncia aos atos delituosos e às condutas perturbadoras da convivência coletiva é, para o autor, um modelo de socialização equivocado. Segundo Costa, a "verdadeira socialização não é uma aceitação dócil, um compromisso de exigências, ou uma assimilação sem grandeza, ela é uma possibilidade humana que se desenvolve na direção da pessoa equilibrada e do cidadão pleno" (Costa, 2001, p. 71). Nela, o jovem “terá a liberdade [o direito] de exprimir, quando isto corresponde à sua vontade ou ao seu entendimento, a indignação salutar que induz à denúncia e ao combate da injustiça e da opressão que povoam a vida dos homens em uma sociedade como a nossa" (idem). Como o próprio autor enfatiza, essa pedagogia está longe de compor o sistema de atendimento ao "adolescente autor de ato infracional"6.

A construção do Sistema Nacional de Atendimento Socioeducativo (Brasil, 2005) representou uma tentativa, nessa primeira década do século XXI, de transformar as práticas de atendimento na execução das medidas socioeducativas. Nesse documento, destacam-se as dificuldades de alteração das práticas, pois é "longa a tradição assistencialrepressiva em relação àqueles que, de alguma forma, transgrediram ou apresentam características de algum risco ou vulnerabilidade social" (Brasil, 2005, p. 14). O quadro apresentado da "realidade institucional do atendimento socioeducativo" aponta as "grandes mudanças necessárias" para que as medidas possam ser "educativas", ou seja, que agenciem uma transformação no sujeito. A função pedagógica das medidas socioeducativas seria a de auxiliar o adolescente, promover atitudes e conhecimentos para que, sobretudo, ele não reincida no ato infracional?.

A aposta nas medidas socioeducativas como um mecanismo de proteção e promoção é um grande desafio para a gestão da política de direitos ao adolescente e para uma pedagogia emancipatória. Como será possível levar a cabo o projeto de uma "pedagogia da presença” em um cenário de serviços burocráticos em que o ideal da punição se sobressai?

Ademais, no Brasil não se ouve falar em socioeducação para jovens que não sejam pobres. Na sociedade brasileira contemporânea, esses jovens

\footnotetext{
5 Gomes da Costa foi diretor da Escola - Febem Barão Camargos, em Ouro Preto/Minas Gerais, no final da década de 1970 e início da década de 1980.

6 Antônio Carlos Gomes da Costa situa a pedagogia da presença como parte de um esforço que "vê o sistema atual como uma massa falida em todos os níveis e aspectos" (Costa, 2001, p. 73), do panorama legal, passando pelo ordenamento político-institucional, até as formas de atenção ao adolescente, que "assumiram contornos de ineficácia e de degradação tão evidentes que tornou-se uma realidade praticamente impossível de ser revestida sem a desconstrução total do sistema” (Costa, 2001).

7 No documento norteador da política nacional de atendimento socioeducativo (Brasil, 2005) as práticas socioeducativas devem tornar o adolescente "um cidadão autônomo e solidário, capaz de relacionar-se melhor consigo mesmo, com os outros e com tudo que integra a sua circunstância, sem que venha a reincidir na prática de atos infracionais" (Brasil, 2005, p. 48); ou ainda "favorecer ao adolescente o acesso às oportunidades de superação de sua situação de exclusão, de ressignificação de valores, bem como o acesso à formação de valores para a participação na vida social" (Brasil, 2005).
} 
são "estranhos" que devem ser inseridos na ordem. A categoria do estranho, segundo Bauman (1998), refere-se aos que não se encaixam no mapa cognitivo, moral e estético do mundo, aos que tornam confusa a linha da fronteira que deve ser vista com clareza pelos que estão inseridos na ordem. Na sociedade dos consumidores, os pobres são os estranhos, e a política voltada para os estranhos é o encarceramento! Viver na pobreza estimularia predisposições ou intenções criminosas (abuso de álcool, drogas, vadiagem, prática de atos ilícitos) que merecem ódio e condenação - como a própria encarnação do pecado (Bauman, 1998, p. 59).

Os adolescentes em cumprimento de medidas socioeducativas costumam viver em territórios estigmatizados, onde há ostensiva presença policial. 0 aprisionamento dos jovens moradores de zonas urbanas de baixa renda constitui política do Estado brasileiro. É uma ação a firmativa carcerária - termo com que Wacquant (2008) caracteriza o estado penal estadounidense - que compõe um amplo processo de criminalização da pobreza.

Como dar vazão à criação de novas possibilidades de vida para o adolescente e, ao mesmo tempo, cerceá-lo em suas concepções de mundo, em sua visão crítica da sociedade?

Entre os pares geracionais, a participação no "mundo do crime" é muitas vezes valorizada. Uma série de características atribuídas ao "ladrão", como as de adotar o risco como estilo de vida, a busca de dinheiro fácil, do poder e do prestígio locais, são elementos de performances corporais e de narrativas dos jovens, que explicitam experiências sobrepostas, adquiridas tanto a partir de relações interpessoais ou institucionalizadas quanto de informações acumuladas em uma ampla representação de falas e imagens públicas, veiculadas pelos meios de comunicação e constantemente ressignificadas na música e no cinema. A identificação com o "mundo do crime" é participar de expressões juvenis de virilidade e força valorizadas por muitos jovens.

Na execução de medidas socioeducativas, costu- ma-se descartar essa dimensão. Com frequência, o ato infracional na adolescência é visto como resultado de uma característica individual do sujeito, que deve ser assistido pela saúde, punido pela justiça e transformado pela educação. Os "delinquentes" são vistos como resultantes de famílias "desestruturadas", com distúrbios de desenvolvimento e que, em razão desses problemas individuais, agridem a sociedade. Esses entendimentos fazem parte de derivações semânticas que limitam a ideia de insegurança aos aspectos psicológico e criminal, excluindo, ou pelo menos desconsiderando, a insegurança social e econômica.

O discurso sobre a responsabilidade pública de educar o adolescente autor de ato infracional e dar-lhe assistência é difundido: há um processo de formação contínua de educadores sociais e o engajamento de profissionais de diversas especialidades que formam o sistema em debates públicos e na formulação de políticas. Entretanto, as iniciativas particularizadas de grupos de indivíduos e organizações não se consolidaram em uma visão de sistema de atendimento, com redes de proteção e oportunidades cidadãs.

O que significa reinserir o adolescente infrator na sociedade? Essa pergunta tem que ser aperfeiçoada por outra: para esses jovens, qual é o significado de habitar o mundo?

\section{Frieza, Cálculo e Sofrimento: a "vida loka" de Elias}

Contarei, a partir de agora, a trajetória, nos últimos seis meses, de Elias ${ }^{9}$, um "quase personagem" que sustenta as ideias que desenvolvo neste ensaio. Trago à tona uma trajetória empírica com o intuito de materializar o sofrimento presente na experiência dos adolescentes em cumprimento de medidas socioeducativas que tenho acompanhado. A escolha dessa trajetória em particular se deve à proximidade que tenho com o adolescente, sua família e sua rede comunitária.

80 termo "ladrão", para esse grupo, refere-se, genericamente, àquele que é reconhecido como envolvido com o "crime", independentemente da modalidade de infração. 0 termo "bandido" costuma ter a mesma acepção.

9 As informações sobre a trajetória de Elias que não observei presencialmente são oriundas de suas narrativas. Os trechos que se referem a acontecimentos e imagens que presenciei são aqueles em que está mencionada minha presença. 
Conheço Elias desde que ele tinha 11 anos de idade; hoje (em 2010) ele tem 16. Trabalhei com sua mãe, dona Ivone, em um projeto social que ocorreu no bairro de moradia da família, em uma cidade da região metropolitana de São Paulo. Elias é filho adotivo de dona Ivone (63) e seu Patrício (61). Conversei com dona Ivone em 2009, após três anos sem nos vermos. Ela me contou, então, que o filho havia "virado traficante". Sua expressão facial demonstrava vergonha. Chegou a cometer um "ato falho", negando ser sua mãe. Quando perguntei a ela se Elias era seu neto - era o que eu pensava - ela respondeu: "meus filhos... são todos honestos".

A casa de Elias é de alvenaria, tem aproximadamente $40 \mathrm{~m}^{2}$ e é situada em um terreno de $150 \mathrm{~m}^{2}$, onde há mais duas casas, de tamanho semelhante, em que moram filhos e netos de dona Ivone e seu Patrício. Famílias extensas, com laços variados além da consanguinidade e uma rede de ajuda e proteção mútua, que difere muito do modelo pretensamente “estruturado" da família nuclear de classe média no Brasil (Fonseca, 2005). Exatamente na frente da casa de Elias, existe um ponto de venda de drogas: uma "biqueira" (ou, como preferem dizer, atualmente, uma "lojinha”). O ponto é estratégico, pois ao lado da casa do rapaz há um beco e, no final deste, um rio e um matagal para onde eles podem fugir da polícia.

Entre janeiro e julho de 2009, Elias ganhou dinheiro, foi preso, recebeu medida de internação, saiu e esteve em cumprimento da medida de liberdade assistida.

No dia 20 de fevereiro, véspera de carnaval, Elias estava vendendo cocaína e crack em frente à sua casa. Eram mais ou menos 23 horas e ele já contabilizava cinco mil reais em vendas e mil e duzentos de lucro para si. De frente de casa, com seu pai a aproximadamente 30 metros, ele viu a polícia chegando: "eu fiquei olhando, olhando para ver se era a força [polícia]... aí, quando eu vi, era mesmo e já estava perto. Aí eu joguei do lado a mercadoria e fui para perto do meu pai que estava na porta do bar". A polícia o abordou, perguntou de quem era a droga e o dinheiro, puxou seu braço, deu uma bronca em seu pai, que não entendia o que estava acontecendo. O pai o acompanhou até a delegacia. Durante o trajeto, uma série de xingamentos e provocações foi proferida contra ele. Elias foi encaminhado para a
Fundação Centro de Atendimento Socioeducativo ao Adolescente (CASA), órgão do Estado de São Paulo responsável pela internação de adolescentes.

Tive a oportunidade de reencontrar Elias na Fundação CASA durante sua internação. Fui convidado, como diretor de uma ONG, para a cerimônia de formatura dos internos. 0 espaço é uma prisão: três complexos de grades, portas e seguranças até chegar ao local onde os adolescentes permanecem. Quando cheguei à última grade, observei-os descendo para o evento: divididos em grupos de cinco, roupas iguais, cabelos raspados, cabeças baixas e mãos para trás, a cada segurança por quem passavam diziam: "dá licença, senhor”, “dá licença, senhora”. Entrei pelo corredor, recebendo indicação da sala para onde deveria me encaminhar. Os adolescentes estavam em uma sala com seguranças, de um lado, e nós fomos para outra, onde seria o evento. Os educadores, psicólogos e outros técnicos ficaram com os convidados. Quando estávamos acomodados, trouxeram os jovens para a sala, 45 ao todo. Antes da distribuição dos certificados do Curso de Empreendedorismo e Turismo, discursaram o representante do poder judiciário, a diretora da unidade de internação, o psicólogo responsável, o presidente do Conselho dos Direitos da Infância e Adolescência e eu, como representante da sociedade civil. Dois educadores cantaram, acompanhados por violão, enquanto os adolescentes eram chamados para receberem seus certificados. Eu estava ao lado da diretora da unidade de internação e comentei com ela como os meninos tinham uma aparência boa, saudável, destaquei o quanto eram bonitos. Ela argumentou que na CASA eles têm dentista, médico, comida boa, dormem bem, não usam drogas, ficam menos vulneráveis.

Para encerrar o evento, alguns adolescentes apresentaram uma dramatização. 0 esquete, singelo, a despeito da desenvoltura de alguns internos, consistia no seguinte: um jovem sai com o diploma da Fundação CASA (curso de turismo, empreendedorismo etc.) para procurar emprego. Ao chegar aos estabelecimentos, o jovem se apresenta e mostra o diploma. Os entrevistadores demonstram apreensão, afastam-se, mudam de assunto, evidenciando preconceito pelo fato de o jovem ter passado pela internação. Elias representava um dos garotos que estava procurando emprego. Em sua performance, 
entrega seu currículo em três lugares diferentes. Sem conseguir uma oportunidade, volta, ao final do dia, para seu bairro e encontra um grupo de amigos que estava trabalhando no "movimento" (tráfico de drogas). Seus amigos o convidam para voltar a trabalhar no tráfico e ele diz que não, não quer, está procurando emprego. Seus amigos estão fumando maconha e circulam o cigarro até a mão de Elias. No momento em que ele segura o cigarro, a polícia chega. Os adolescentes da CASA riram bastante após a apresentação, comungando significados. A mensagem que transmitiram foi patente: independentemente do que façam, ou deixem de fazer, serão sempre considerados suspeitos; ao saírem da internação, sua marca será a de ex-internos da "Febem" ${ }^{\circ}$.

Elias ficou aproximadamente dois meses internado. 0 prazo de internação não é predeterminado; depende da decisão do juiz, que costuma seguir a indicação apresentada no laudo dos técnicos da Fundação CASA. Geralmente, os laudos são assinados por psicólogos. Não tive acesso ao laudo de Elias, mas dona Ivone me mostrou uma carta enviada por ele que sensibilizou a psicóloga a ponto de ela escrever um relatório recomendando a soltura do rapaz. $\mathrm{Na}$ carta, endereçada à mãe, Elias aponta uma mudança comportamental: "Aqui descobri que o crime não compensa, tô no sofrimento, mãe. Me perdoa, mãe; tô aprendendo uma profissão, pra lá fora enfrentar o mundão. Vou me armar com enxadas e pá; minha mão calejar. Cuidar bem da minha família, uma família firmona, mãe. Só tenha uma certeza: de que um dia seu filho vai voltar."

No início de abril, Elias foi solto e iniciou o cumprimento da medida de liberdade assistida (L.A). Encontrei-o na segunda semana de atividades da L.A., quando ele foi para uma oficina de rap, na qual eu atuava como facilitador, voluntariamente. Ao final da atividade, levei-o para sua casa e ficamos por mais ou menos uma hora conversando. Perguntei a ele o que era a L.A. "É um documento que eu assino, para o juiz ver que eu estou indo lá, estou compare- cendo, estou fazendo o que ele pede... Tem Conselho, tem carro à paisana e tem polícia... Tudo de olho em mim; na guarda do juiz. Aí, na escola... eu ando na rua, assim, ele sabe tudo. Ele sabe aonde eu vou, o que eu faço, da escola... Eles vão lá; perguntam como eu estou". "Eles quem?”, perguntei. "Os policiais”. E continuou a descrição da relação que imagina ter (ou que de fato tinha) com as instituições do sistema socioeducativo. "Só que eu não sei disso, né? A psicóloga é que me avisou. Ela falou; 'o juiz tá na sua cola; ele tá com olho deste tamanho em você [o garoto fez o sinal com a mão abrindo os olhos]; pensa que não tem ninguém de olho em você? Mas a polícia, a diretora da escola, tá todo mundo de olho em você." Perguntei o que ele pensava disso. "Não vou falar que eu acho bom, porque fui eu que cometi este erro e tenho que pagar. Deixei vergonha na família, joguei o nome da minha família na lama".

Ao deixá-lo em casa, conversei com dona Ivone e pedi permissão para visitá-los uma vez por semana. Ela demonstrou satisfação. Temos uma relação de amizade, convivemos com certa intimidade durante três anos. Elias também pareceu gostar, talvez tenha sido apenas simpático. Voltei durante três semanas consecutivas, por volta das $11 \mathrm{~h}$ da manhã e Elias estava sempre dormindo. Em um dos dias, sua mãe me disse que estava desconfiada de que ele havia voltado para o "crime". Disse que "é uma judiação" o que acontece com os jovens de hoje em dia, que muitos "meninos do tráfico" cresceram em sua casa, eles eram "bons”. Insistiu para que eu voltasse para conversar com Elias.

Voltei no dia combinado, 10 de junho. Elias estava no bar conversando com alguns homens mais velhos, um travesti e um amigo, este sentado em uma bicicleta. "É o gerente da biqueira", disse-me a tia de Elias. Dona Ivone saiu ao portão no momento em que cheguei e começou a gritar com Elias e seu colega da bicicleta. "Olha, menino", dizia se dirigindo ao rapaz de bicicleta, "eu não quero mais você aqui na porta da minha casa, que história é essa que você plantou maconha no meu jardim?" Começaram a

10 Atualmente a instituição responsável pela privação de liberdade de adolescentes no Estado de São Paulo é a Fundação Centro de Atendimento Socioeducativo ao Adolescente (CASA), Apesar de o nome ter mudado em 2006, grande parte da população chama a fundação pelo antigo nome, Febem, que é identificado popularmente como sinônimo de prisão de adolescentes "bandidos" e "perigosos". 
bater boca. Elias manteve distância, como se fosse absolutamente indiferente ao ocorrido. Dona Ivone chamou Elias: "Você acha que vai ser alguma coisa sendo traficante? Você não vai ser nada. Meus filhos são todos trabalhadores, agora você, que eu adotei e cuidei como se fosse meu filho, faz isso". Elias continuava a expressar indiferença. "Você sempre foi frio e calculista", disse dona Ivone. Elias riu, talvez porque visse essas características como qualidades. Dona Ivone, até então com uma expressão severa, riu, resignada.

Em um sábado de junho, voltamos a nos encontrar. Convidei Elias para ir até o centro da cidade. Era o aniversário da cidade. Tradicionalmente, acontece um desfile cívico de que todas as escolas e ONGs da cidade participam. Conversei com dona Ivone, enquanto aguardava o garoto, e ela falou de seus problemas de saúde, dando a entender que as preocupações com Elias deixavam-na desgostosa. Dona Ivone mudou de perspectiva repentinamente, apontando uma percepção muito pessoal sobre seu filho e os amigos dele. Lembrou-se dos vários meninos que hoje estão no tráfico e "cresceram" em sua casa. Ela atribui ao ganho "fácil" - e tudo o que o acompanha, como boas roupas, utensílios tecnológicos, lazer, mulheres - a grande motivação para os jovens aderirem ao tráfico. "Essa geração de hoje é muito difícil. Eles têm outra cabeça”.

Elias saiu de casa pronto para ir comigo ao centro da cidade. Vestindo um casaco vermelho de gola alta fechada por uma corrente dourada, tênis Nike brilhando de novo, bermuda larga vermelha e um boné azul e vermelho; estava animado com o passeio. Chegamos ao centro e ele caminhava com um estilo facilmente reconhecido pelos seus pares geracionais. Passos largos, cabeça erguida, gestos largos com as mãos para cumprimentar as pessoas. Percebi olhares de admiração e outros de atenção de muitos jovens que o conheciam, e não eram poucos. Paramos, então, em uma lanchonete, onde havia um grupo de amigos dele. Ele se sentou e ficou conversando. Fiquei alguns minutos com o grupo, composto de alguns jovens de estilo parecido, outros não. Despedi-me do grupo, pois tinha que acompanhar o desfile de uma ONG em que eu havia trabalhado. Quando voltei, os garotos estavam desolados na praça em frente à lanchonete. Eles haviam sofrido uma "batida" policial na frente de centenas de pessoas que acompanhavam a festa. 0 dono desconfiou de que eles pudessem estar observando o local para tramar um assalto - pelo menos foi isso que o policial argumentou segundo a versão dos jovens. Elias, que estava imponente, vaidoso, agora mostrava expressão de revolta e humilhação. Ao deixá-lo em casa, no momento exato em que chegamos, a polícia passava lentamente em frente à sua casa. Os policiais olharam com agressividade para nós, como se fossemos suspeitos.

Na última visita à casa de Elias, em 29 de julho, aconteceu algo inesperado. Ele estava no bar em frente à sua casa. Ficou meio sem jeito. Percebi que ele estava vendendo drogas. Chegou, então, um rapaz de, aparentemente, 20 e poucos anos, cabelo com reflexos loiros, correntes de prata, dirigindo um Vectra ${ }^{11}$ azul metálico, com equipamento de som de última geração, e chamou Elias para ir com ele comprar vinho em uma adega tradicional da cidade. Elias me perguntou se eu sabia onde era a tal adega. Eu sabia. Então, o rapaz me chamou para ir com eles. Entramos no automóvel e saímos em direção ao local. Carro impecável, com equipamento de som tocando Racionais $M C^{\prime}$ 's, o grupo de rap mais conhecido do Brasil. A caminho, descobri que o rapaz não tinha carteira de habilitação. Fiquei um pouco apreensivo, mas percebi que estava em uma situação interessante para a pesquisa e tinha que seguir adiante.

Avisei ao condutor do automóvel que era costume haver "comandos" (blitz com parada e inspeção de carros e condutores) na entrada da cidade. Paramos de esquina em esquina, observando de longe se havia algum "comando". Conseguimos entrar na autoestrada que contorna a cidade, antes de passarmos pela polícia. Seguimos até a última entrada e nos dirigimos à adega. Os rapazes compraram o vinho e conversaram um pouco com um "senhor" sobre os processos de produção da bebida.

Creio que pelo gosto do risco e da aventura, o

11 Automóvel da marca GM. 
rapaz resolveu voltar pelo centro da cidade, mesmo estando em um carro rebaixado, com som bem alto, tocando rap, sem usar o cinto de segurança, além da falta da carteira de habilitação, o que, com exceção de ouvir rap, são infrações às leis de trânsito. Enquanto passávamos pelas ruas centrais, o rapaz comentou que não via o centro há uns dois anos, pois saíra da cadeia há cinco semanas. Os dois observavam todas as ruas, as pessoas, os prédios do centro. Passamos, inclusive, em frente a policiais. Com o vinho aberto rodando de mão em mão, bebido a goles amplos e contundentes, os dois cantavam com fúria uma canção dos Racionais MCs, desempenhando com gestos, poses e expressões faciais.

Deixa eu fala, pocê, tudo, tudo, tudo vai, tudo é fase irmão, Logo mais vamos arrebentarno mundão, de cordão de elite, 18 quilate, põe no pulso, logo bright, que tal, tá bom [...] pobre éo diabo, eu odeio ostentação, pode rir, ri, mas não desacredita não,é só questão de tempo, o fim do sofrimento, um brinde pros guerreiro, zé povinho eu lamento, vermes que só faz peso na Terra, tira o zóio, tira o zóio, vê se me erra" [...] Quente é Mil Grau, O que o guerreiro diz, o promotor é só um homem, Deus é o juiz, enquanto zé povinho apedrejava a cruz, um canalha fardado, cuspiu em Jesus, Hó... Aos 45 do segundo arrependido, salvo e perdoado, é Dimas o bandido, é louco o bagulho, Arrepia na hora, Dimas primeiro vida loka da historia, eu digo, glória... Sei que Deus ta aqui, e só quem é, só quem évai sentir, e meus guerreiro de fé, quero ouvir [...] inconscientementevem na minhamente inteira uma loja de tênis, o olhar do parceiro feliz de poder comprar o azul, o vermelho, o balcão, o espelho, o estoque, a modelo, não importa, dinheiro é puta e abre as portas, dos castelos de areia que quiser [...] o seu enterro foi dramático como um blues antigo, mas de estilo me perdoe de bandido, tempo pá pensar, quer parar, que se quer, viver pouco como um rei, ou muito como um Zé (Vida Loka, parte 2, Racionais Mc's) ${ }^{12}$.

A ideia de "vida loka", expressa nesse rap, é comumente utilizada em periferias paulistas, publicada em adesivos colados em carros, pichações em muros, e síntese do imponderável na casualidade. Ela parece revelar a imponderabilidade da experiência comum, o aparente caos que cada indivíduo deve gerenciar, mas, também, o reconhecimento de que o mistério do fluxo da vida cotidiana não é controlado pelo Estado ou por qualquer poder humano. Especificamente no cotidiano de jovens que participam do "crime", a expressão "vida loka" sintetiza o assombro e a dor daqueles que estão situados como a vida matável ${ }^{13}$ preferencial na sociedade brasileira contemporânea. A complexidade da "vida loka" no interior do "crime" leva o jovem a um dilema: sair dele e procurar viver como um "Zé", realizando trabalhos enfadonhos e mal remunerados, comuns aos moradores das periferias paulistas, sem acesso ao mundo de bens desejados, ou continuar vivendo como "Rei", ainda que de maneira fugaz e perigosa.

Não mantive convívio com Elias. Em uma das poucas vezes em que me encontrei com ele, nas ruas do bairro, presenciei mais uma vez seu dilema. Ele estava com outro jovem que conheço desde a época em que trabalhava em uma ONG da cidade. Esse jovem, hoje, é gerente (coordenador de vendas) de uma "biqueira". Elias "tomou um enquadro da polícia" e fugiu da "lojinha", passando uma semana sem trabalhar. No momento em que os encontrei, eles conversavam sobre esse fato. 0 gerente dizia que Elias não servia para o crime, pois se no "primeiro enquadro que você toma da polícia já some... ladrão não fica entre a cruz e a espada; ladrão é ladrão".

12 Nada como um dia após o outro dia. São Paulo. Cosa Nostra. 2002. Diversas expressões presentes na música são comuns no vocabulário de jovens moradores de periferias paulistas. A proposta aqui não é fazer uma interpretação da letra. Considero importante apenas destacar que o personagem "Dimas", se refere à história do bandido que estava ao lado de Jesus Cristo no momento da crucificação e foi "perdoado" por Deus e "salvo".

13 Giorgio Agamben utiliza a expressão Homo sacer (figura do direito romano arcaico) para caracterizar a vida nua, exposta ao poder soberano. Esse Homo sacer se define pelo homicídio que qualquer um pode cometer contra ele sem punição. Segundo Agamben, a biopolítica - a crescente implicação da vida natural do homem nos mecanismos e nos cálculos do poder estatal - revela a política do ocidente moderno. Assim, no interior de cada sociedade, define-se a vida que cessa de ser politicamente relevante, as "vidas que não merecem ser vividas". (Agamben, 2007). 
Ambiguidades da Execução de Medidas Socioeducativas na Vida de Adolescentes em Conflito com a Lei

A trajetória de Elias possui especificidades, porém é exemplar em diversos aspectos. Nos programas em que acompanho adolescentes em cumprimento de medidas em meio aberto, observo as ambiguidades que se impõem à suas experiências. A transição da medida de privação de liberdade para uma medida em meio aberto marca a possibilidade de mudança dos projetos de vida ${ }^{14}$. Em todos os casos que acompanho, as dificuldades de alcance desse fim são enormes, a despeito do esforço de educadores e técnicos, que desenvolvem atividades educativas interessantes e engajadas. A marca de privação de liberdade torna difícil a relação com a escola e, ainda mais, a possibilidade de inserção no mercado de trabalho. A ação da polícia tende a se intensificar após a internação, tornando o adolescente mais facilmente identificado como suspeito. A trajetória de Elias revela situações de sofrimento comuns a outros adolescentes a quem tenho pesquisado.

As expressões de Elias durante a internação olhar perdido de desamparo e, ao mesmo tempo, reflexivo e resignado - inscrevem em seu corpo a presença do delito como demonstração de uma falta individual de um adolescente. A possibilidade de ter uma recaída é a marca de seu lugar social no mundo institucional. O que o juiz exige, como condição para o adolescente ser considerado "recuperado" e sair da internação, são pareceres técnicos que indiquem que ele não reincidirá e a presença dos pais para garantir que ele não tenha uma recaída. Quanto menos autônomo e mais afeito às expectativas institucionais, quanto mais submisso, em seus atos e falas, ao discurso institucional, maior é a chance de o adolescente em conflito com a lei ser considerado saudável e pronto para se reinserir na sociedade sem o "risco" de voltar a cometer um crime. Em sua relação com os representantes do sistema socioeducativo, Elias representou o comportamento esperado para ser solto. Privado de liberdade, o adolescente percebeu que é por meio do "bom comportamento", de seu “ajuste", que se dá a possibilidade de absolvição. As expressões faciais e a gestualidade do corpo, nos momentos em que pude presenciar sua relação com os representantes institucionais, foram marcadas por elementos de uma performance de submissão - mãos para trás, cabeça baixa, expressões de resignação que diferem substancialmente de sua linguagem, seus gestos e movimentos na rua, entre seus pares. A mudança comportamental durante a internação não representa, contudo, necessariamente, manipulação ou falsificação de suas "reais intenções". Sua fala sobre a "vergonha que deixou na família" indica a interiorização da culpa e a dúvida com relação a suas escolhas.

Elias expressa, sem dizer, que não se submete. Ele lida com a lógica do Estado para se manter livre, manejando seu comportamento e narrativas. Essa lógica, ao chegar à consciência familiar, o coloca em uma situação de sofrimento ainda maior. Continuar a ser um "ladrão" significa desonrar aqueles que o amam. Na rua, entretanto, ele manteve a performance que o identifica como alguém de estilo "de bandido" - como se canta no rap dos Racionais. Nos momentos em que se apresenta a seu grupo de relações, nas "baladas" (diversões, geralmente em bares e danceterias) noturnas, em contextos nos quais pode seduzir e usar seu dinheiro, ele tem posturas corporais, gestos e movimentos de força, altivez, coragem. Ele sabe que, assim, recebe a atenção de garotas e o respeito de garotos. Desempenha com desenvoltura o estilo "bandido" e parece sentir-se adequado a ele. Esse estilo não é estranho a seus amigos, sejam do "mundo do crime" ou não.

A mãe navega na ambivalência da situação do filho: ora defende uma moral de valorização do trabalho e da família e se mostra no limite do abandono de seu filho "bandido" (nesse caso, destacado como adotivo), ora é capaz de expressar sensivelmente o reconhecimento da diversidade de Elias e seus amigos ou colegas que flertam com o "mundo do crime”. A família sofre uma investida do Estado,

14 Segundo o ECA, Art. 118, a medida de liberdade assistida será adotada sempre que se afigurar a medida mais adequada para o fim de acompanhar, auxiliar e orientar o adolescente. É uma medida bastante comum para adolescentes que passaram pela internação e deve promover socialmente o adolescente e sua família, supervisionar a frequência e o aproveitamento escolar, esforçar-se no sentido da profissionalização do adolescente e de sua inserção no mercado de trabalho (Brasil, 1990) 
que causa mais dor do que contribui para o fortalecimento dos laços afetivos entre os parentes, um dos objetivos propalados pelo sistema socioeducativo. Acompanhando Veena Das, no retrato que observei do conflito entre as gerações em meio a uma intervenção institucional:

Fica evidente a existência de formas narrativas, simbólicas e sociais, nas quais se tece uma violência difusa [...] no processo de sua articulação, às vezes de sua prática, a violência parece definir os contornos dentro dos quais ocorre a experiência de uma forma de vida enquanto forma de vida humana (Das, 1999, p. 36).

As medidas socioeducativas não são apenas uma estratégia punitiva, mas um tipo de pena que tem como foco e sentido o ajuste pedagógico e psicológico do adolescente. Um argumento, bastante usado por alguns técnicos e profissionais ligados ao sistema é o de que a internação pode ser boa para o adolescente. Nessa concepção, a privação de liberdade protege o adolescente dele mesmo. Segundo Frasseto (2006), a medida socioeducativa de privação de liberdade se constitui em uma sanção destituída de mecanismos de controle social. $O$ adolescente fica em situação de total subordinação à pretensão repressiva do Estado. Ele só terá a liberdade se passar por uma avaliação psicológica positiva. A essência da medida é conseguir que o adolescente apresente a modificação de seus aspectos subjetivos. O Estado responsabiliza o sujeito pelo que ele é, não pelo que ele faz (Frasseto, 2006). Como consequência, a resposta do Estado não são políticas públicas articuladas, mas o tratamento dos "desviantes", porque é neles que reside a semente da "delinquência". Esse modelo de intervenção em que se concebe a marginalidade como uma incapacidade do indivíduo estava presente na Febem dos anos 1980 (Violante, 1982) e se reproduz, como parte do "entulho autoritário" que a sociedade brasileira hoje se vê chamada a desmontar (Costa, 2001).

No processo de execução das medidas socioeducativas, a família é chamada pelo Estado para tratar da cidadania que falhou, por meio de encontros com psicólogos, assistentes sociais e representantes da justiça. O que é responsabilidade do Estado e da sociedade é minimizado, e todo encargo pela reincidência do ato infracional recai sobre a família e o indivíduo. Com esses procedimentos, parece-me que dona Ivone, mãe de Elias, sentiu-se impelida a reforçar o discurso institucional como uma obrigação moral, embora reflita sobre a situação de seu filho e dos amigos dele, que ela viu crescer. A ação do Estado, aplicada dessa forma, interfere e no papel de cada um dentro da família e o influencia, levando à opressão dos adolescentes em seu próprio lar.

Após a "batida" policial e a situação constrangedora pela qual passou na lanchonete, no dia de aniversário de sua cidade, Elias narrou sua revolta e dor. Ele contou com indignação o que ocorrera. "Eu vou traficar mesmo", falou com raiva. Naquele momento, pelo vínculo que tenho com ele e seus parentes, procurei dissuadi-lo. Tentei alertá-lo para o fato de que essa escolha só reforçaria a repressão da polícia e o sofrimento dele e de sua família. Ele disse que sua mãe sempre trabalhou como doméstica, do outro lado da cidade, e que nunca teve nada. Que sempre foi explorada e que ele não queria essa vida. "Eu nasci aqui na favela, eles nunca vão me dar um 'boi15"”. Perguntei-lhe: "Eles quem?", "A sociedade", ele respondeu. "Prefiro viver pouco como um rei do que muito como um Zé", foi o que consegui interpretar de sua defesa no estilo "bandido". Esse foi o lugar em que ele se posicionou naquele momento de humilhação.

Os jovens passam pelo sofrimento de uma intervenção repleta de ambiguidades, porque essa condição é imposta a eles como algo feito para protegê-los deles próprios e de seu contexto de "vulnerabilidades". A representação dramática de que Elias participou indica que a marca da privação de liberdade na Fundação CASA para os adolescentes é um estigma de segregação dificilmente superado. A "dramatização" revelou a leitura que eles fazem de suas próprias experiências entre as fronteiras do consumo e o tráfico de drogas, da pobreza, do preconceito e da falta de oportunidades. De forma crescente, os adolescentes são presos por crime de tráfico. Na singeleza do teatro, os jovens internos exibiram o sentimento de risco constante que sofrem. Eles podem perder a liberdade por consumirem

15 A expressão "dar um boi” significa dar uma chance, uma oportunidade. 
ou venderem drogas em pequenas quantidades.

No "mundo do crime" é preciso "ter uma mente", é necessário ser inteligente, pois a "vida é loka”. "Frieza" e "cálculo" são qualidades necessárias no mercado das drogas. A partir das diversas falas e comportamentos que observei na pesquisa de campo, interpreto a noção de "inteligência" como atributo dominante no "mundo do crime", como a de ter capacidade de administrar a vida cotidiana. "Ter uma mente" combina com uma inteligência prática, que integra senso de oportunidade e a arte de contornar situações difíceis, comum à "viração" das classes populares (Teles e Hirata, 2007). Na rua, Elias percebe que está ali, na frente de sua casa, a possibilidade de levantar, em tempos de crise, R\$ 70o,oo reais em uma semana ${ }^{16}$. E, como ele mesmo diz: "Eu não vou na casa de ninguém levar droga; eu não obrigo ninguém. Eles vêm aqui e eu vendo”. Outra ideia recorrente na fala dos garotos é a de que, no tráfico, eles "não matam nem roubam" para ganhar seu dinheiro. Portanto, moralmente, Elias questiona: “qual é o problema?". Sabemos: ele vende mercadorias consideradas ilegais no Brasil, embora seu uso já constitua uma prática amplamente difundida.

A liberdade assistida não representa, para Elias, uma prática que proporcione autonomia ou que melhore sua autoestima. Ele saiu da internação, mas a marca de "presidiário" já está em sua "pele". Ele vê a L.A. como um ritual burocrático que deve ser cumprido para atender à determinação do juiz. Identificou na medida um controle total, um "big brother", em que o juiz representa o poder central, a psicóloga a "mensageira", a polícia e a escola os "tentáculos" que, em seu próprio território, o observam e o constrangem. Até dentro de sua casa, por meio de sua mãe, a visão normativa do Estado se impõe durante o cumprimento da medida socioeducativa.

A participação no "crime" revela-se como uma experiência cotidiana em que ocorre um conjunto de situações de opressão e violência. Ao mesmo tempo, revela um modo de oposição ao que chamam de "sistema" ou "sociedade". Muitos jovens em cumprimento de medidas socioeducativas que conheço questionam até que ponto o "sistema" é para eles.
Impõem resistência ao modelo de sociedade da qual são parte no Brasil contemporâneo. Essa resistência se perpetra pela forma com que os jovens dispõem da linguagem e de seus corpos, no estilo "bandido". Elias interioriza sua posição em um campo de relações de poder e passa pelo extremo sofrimento de viver "no fio da navalha", inaceitável para toda sua rede de relações. Para os operadores do sistema socioeducativo, ele deve se mostrar firme, disposto a "pegar na pá e na enxada”, se for necessário. Para o sistema do crime, "ladrão não fica entre a cruz e a espada”. Elias não pode ter dúvidas, embora a vida seja imponderável, "loka".

\section{Considerações Finais}

Como antropólogo e profissional na área da infância e juventude, busco a compreensão de como os direitos são sentidos e vividos por aqueles que são punidos com base legal. Uma das maneiras que os adolescentes têm de manifestar o ressentimento e a angústia que sentem, apresenta-se em suas performances e narrativas de sofrimento. Se os programas de atendimento socioeducativo não atentarem ao que o sofrimento e a rebeldia dos adolescentes apresentam em termos de um conflito social, continuarão a fazer uma leitura estritamente normativa (patologizante e judicial) para explicar o ato infracional. Dessa forma, será muito difícil capturar o que está além do indivíduo que comete um crime. Não se considerarão uma série de situações cotidianas que os jovens, sobretudo os pobres, estão experimentando e que podem nos revelar fraquezas institucionais e ambivalências da sociedade brasileira.

Ao situar os adolescentes como sujeitos de direitos, o sistema socioeducativo passa a representar a possibilidade de eles mudarem o comportamento desviante e assim tornarem-se membros da sociedade. Dessa forma, o Estado faz a sua parte, cumpre suas funções racionais de controle da criminalidade e, ao mesmo tempo, de promoção da cidadania. 0 Estado garante o direito ao jovem de se ressocializar, permite que ele, por meio de sua razão individual, possa transpor a fronteira do "mundo do crime".

16 Grande parte dos adultos moradores do bairro de Zezinho ganha entre um e dois salários mínimos ao mês. O salário mínimo no Brasil, hoje (abril de 2010), é de R\$ 520,oo, equivalentes a US\$ 297,82. 
Se o adolescente não a transpuser, isso será uma fraqueza individual ou da família. Cria-se uma noção de diversidade entre jovens aptos a voltarem ao convívio social e jovens reincidentes.

Muitos adolescentes, entretanto, reincidem após terem passado por medidas socioeducativas. Aconteceu com Elias e acontece com parte significativa dos adolescentes que passam pela privação de liberdade. Entre os adolescentes que acompanho, apenas três não reincidiram. Jéssica, após a privação de liberdade, "saiu tão transtornada" e com "tanta raiva da polícia" que queria voltar a traficar e se vingar da violência que sofreu ao ser presa, mas logo que voltou para o "movimento", um colega do tráfico foi assassinado com 19 tiros; esse fato, aliado a uma crise de hipertensão de sua mãe, fez com que ela abandonasse o "crime". Richarlisson não reincidiu, começou a trabalhar no "lava-rápido do tio" e a namorar uma "menina evangélica”. Kelli engravidou e voltou para a casa dos avós, que tinham uma "condição de vida melhor" e viviam em uma cidade do interior ${ }^{17}$. Os motivos são casuais, embora os adolescentes "não reincidentes" ressaltem a importância do acompanhamento e das oficinas do programa de atendimento socioeducativo que frequentam. A qualidade das práticas socioeducativas contribui para o desenvolvimento pessoal dos adolescentes, mas eles parecem necessitar de uma ajuda do acaso para evitar a reincidência. Não observo, em minha pesquisa, a efetivação de uma rede de políticas e serviços públicos que garanta ao adolescente o acesso a oportunidades cidadãs, tampouco o sistema está estruturado para satisfazer as condições da "pedagogia da presença".

Acompanhamos situações cotidianas, em certo sentido imponderáveis, que delimitaram os contornos de uma forma de vida humana. No momento em que me disse que iria continuar traficando, Elias se autojustificou. Disse que sua mãe nunca teve nada e que ele nunca teria uma oportunidade. A transgressão foi explicada por um discurso que enfatiza a injustiça social no Brasil contemporâneo.
Uma leitura precipitada pode indicar uma consciência racional e política nos moldes de movimentos políticos que se opõem à violência do Estado. Pareceme, todavia, que a obstinação contra o "sistema", manifesta nas falas e nas performances estilo "bandido" de Elias, se constitui em uma resposta ao discurso dominante no sistema socioeducativo, contexto em que é muito difícil para ele responder às demandas que lhe são exigidas. Essa impossibilidade é experimentada no cotidiano: como lidar com uma "vida loka"?

As medidas socioeducativas agem sobre adolescentes demarcando a dificuldade de inserção de amplos segmentos de jovens na sociedade dos consumidores, no mercado de trabalho dignamente remunerado e no processo de formação qualificada. A despeito dos esforços de intelectuais e profissionais (dos quais eu faço parte) em construir práticas que garantam direitos e contribuam para o desenvolvimento pessoal dos adolescentes, a execução de medidas socioeducativas compõe um quadro em que o Estado brasileiro mantém o paradoxo ${ }^{18}$ de garantir uma democracia formal enquanto viola direitos civis e estigmatiza segmentos da juventude brasileira.

\section{Referências}

AGAMBEN, G. Homo Sacer: o poder soberano e a vida nua. Belo Horizonte: UFMG, 2007. 207 p.

BAUMAN, Z. Os estranhos da era do consumo: do estado de bem-estar à prisão. In: BAUMAN, Z. 0 Mal-estar da pós-modernidade. Rio de Janeiro: Zahar, 1998, p. 49-61.

BRASIL. Lei no 8.069, de 13 de julho de 1990. Dispõe sobre o Estatuto da Criança e do Adolescente e dá outras providências. Brasília, Diário Oficial da União, 1990.

BRASIL. Secretaria Especial de Direitos Humanos. Documento referencial para o Sistema Nacional de Atendimento Socioeducativo. Brasília, Secretaria de Direitos Humanos, 2005. 123 p.

17 Informações colhidas em depoimentos e sistematizadas em diário de campo durante o ano de 20og. Os nomes dos adolescentes são fictícios.

18 Teresa Caldeira (200o) dá o nome de democracia disjuntiva ao paradoxo da história recente do Brasil, em que o estado de direito coexiste com a violação de direitos civis. 
CALDEIRA, T. P. R. Cidade de muros: crime, segregação e cidadania em São Paulo. São Paulo: EDUSP, 2000. 399 p.

CARVALHO, C. Violência e sofrimento social: a resistência feminina na obra de Veena Das. Saúde e Sociedade, São Paulo, v. 17, n.3, p. 9-18, set. 2008.

COSTA, A. C. G. A presença da pedagogia: teoria e prática da ação socioeducativa. São Paulo: Global: Instituto Ayrton Senna, 2001. 202 p.

DAS, V. Life and works: violence and descent into the ordinary. Berkeley: University of California Press, 2007. 285p.

DAS, V. Fronteiras, violência e o trabalho do tempo: alguns temas wittgensteinianos. Revista Brasileira de Ciência Sociais, São Paulo, v. 14, n. 40, p. 31-42, jun. 1999.

FERREIRA, R. M. Meninos da rua. Valores, expectativas de menores marginalizados em São Paulo. São Paulo: Comissão de Justiça e Paz de São Paulo, 1980. 173 p.

FONSECA, C. Concepção de família e prática de intervenção. Saúde e Sociedade, São Paulo v. 14, n. 2, p. 50-59, ago. 2005.

FRASSETO, F. A. Execução de medida socioeducativa de internação: primeiras linhas de uma crítica garantista. In: ILANUD; ABMP; SEDH. UNFPA (orgs.) Justiça adolescente e ato infracional: socioeducação e responsabilização. São Paulo: ILANUD, 2006. p. 303-342.
GEERTZ, C. Nova luz sobre a antropologia. Rio de Janeiro: Zahar, 2001. 248 p.

GOLDMAN, M. Alteridade e experiência: antropologia e experiência etnográfica. Etnográfica, Lisboa, v. 10, n. 1, p. 161-173, maio 2006.

KLEINMAN, A.; DAS, V.; LOCK, M. (ed.). Social suffering. Berkeley: University of Califórnia Press, 1997. $404 \mathrm{p}$.

MANO BROWN. Vida Loka II. Intérprete:

Racionais MC's. In: RACIONAIS MC'S. Nada como um dia após o outro. São Paulo: Cosa Nostra, 2002. 1 CD. Faixa 7.

SCHNEIDER, L. Marginalidade e delinqüência juvenil. São Paulo: Cortez, 1982.156 p.

TELES, V. HIRATA, D. Cidade e práticas urbanas: nas fronteiras incertas entre o ilegal, o informal e o ilícito. Revista Estudos Avançados, Dossiê Crime Organizado, São Paulo, v. 21, n. 61, p. 173-191, dez. 2007.

VIOLANTE, M. L. O Dilema do decente malandro. São Paulo: Cortez, 1982.196 p.

WACQUANT, J. A penalização da miséria e o avanço do neoliberalismo. In: WACQUANT, J. As duas faces do gueto. São Paulo: Boitempo, 2008. p. 93-105. 